\title{
Analysis about the Behavior and Modeling of pH-Sensitive Hydrogels with Different Ratios of Chitosan and Polyvinylpyrrolidone
}

\author{
Daniela Ribeiro $\mathbb{D}^{\circ}$, Gabriel Yuto, Silvia Lenyra Meirelles Campos Titotto \\ Center of Engineering, Modelling and Applied Social Sciences, Federal University of ABC, Santo André, Brazil \\ Email: daniela.ribeiro@aluno.ufabc.edu.br
}

How to cite this paper: Ribeiro, D., Yuto, G. and Titotto, S.L.M.C. (2019) Analysis about the Behavior and Modeling of $\mathrm{pH}$ Sensitive Hydrogels with Different Ratios of Chitosan and Polyvinylpyrrolidone. Journal of Materials Science and Chemical Engineering, 7, 64-76.

https://doi.org/10.4236/msce.2019.78008

Received: July 15, 2019

Accepted: August 23, 2019

Published: August 26, 2019

Copyright $\odot 2019$ by author(s) and Scientific Research Publishing Inc. This work is licensed under the Creative Commons Attribution International License (CC BY 4.0).

http://creativecommons.org/licenses/by/4.0/

cc) (i) Open Access

\begin{abstract}
Smart material can be defined as a material that can dock or convert energy between physical domains or as a material that can generate a response, in their characteristics, properties or geometries, when submitted to an external stimulus, for example, to heat, water presence, light, etc. In this paper, the second definition will be approached. Hydrogels are crosslinked materials that can absorb a big amount of water. They generally can be considered as smart materials once they exhibit sensibility to external stimuli like to $\mathrm{pH}$ variation, as will be approached in this paper. Thus, chitosan/polyvinylpyrrolidone hydrogels of three different ratios between these two polymers (1:1, 7:3 and 3:7) were synthesized and putted in aqueous solution with different $\mathrm{pHs}$. The $\mathrm{pH}$ was adjusted adding drops of $\mathrm{NaOH}$ and $\mathrm{HCl}$, slowly. After the collection of results and in order to understand the phenomena in a visual way, models of the molecules were also elaborated using the Avogadro software. Therefore, it was possible to realize that the greater the ratio of chitosan in the hydrogel, the greater its sensitivity to $\mathrm{pH}$. Such characteristic is associated with the amino $\left(-\mathrm{NH}_{2}\right)$ groups in it structure, which are capable of protonating and deprotonating (depending of the $\mathrm{pH}$ ), generating charges under the chemical structure of the material, which will expand its volume in order to minimize the repulsion between charges. In addition, it was also noted that the hydrogel expansion is inversely proportional to the $\mathrm{pH}$ increase. By practical tests, it was possible to conclude that chitosan/PVP hydrogel with ratio $7: 3$ is the most interesting once it presented a greater quantity of chitosan in its composition, what implied in more rigidity than the others and greater ease of handling, resulting in more reliable results. This hydrogel also showed higher sensitivity to $\mathrm{pH}$.
\end{abstract}

\section{Keywords}

Chitosan, Hydrogel, Smart Material, pH Sensitivity, Polyvinylpyrrolidone, 


\section{Introduction}

Hydrogels are three dimensional crosslinked polymeric networks that are able to absorb a big amount of water and/or biological fluids [1]. They usually are transparent, biocompatible and inexpensive materials that can be utilized for create materials such as actuators, ionic skins, drug delivery devices, etc. [2] [3]. For these and others applications, the hydrogel applied needs to be sensible to an environmental condition. For the drug delivery device, the hydrogel will only release drug to the body if it detects some change and be sensible to it. For example, if it is sensible to $\mathrm{pH}$ variation, it can break and release some component that was inserted on it.

Chitosan is a copolymer of $\mathrm{N}$-acetyl-glucosamine and glucosamine that can be used to produce sensible hydrogels [4]. It is derived from the deacetylation of chitin and its properties depend on the degree of deacetylation. For example, if the degree of deacetylation is high, chitosan is quite soluble and if the degree of deacetylation is low, the material is quite biocompatible [5]. In general, chitosan is non-toxic, biodegradable and has high capacity to absorb water [4] [6] [7].

This linear polysaccharide has amino groups that are capable of ionizing, depending on the $\mathrm{pH}$ of the material [8], and on connecting with species like ions, phosphates, etc. [9].

In this way, the material is called smart, since it presents a response to external stimuli [10]. Such behavior will be explored and demonstrated experimentally in this paper.

However, it is important to mention that there is a discussion about the definition of "smart material". Some researchers define it as materials that can dock or convert energy between physical domains, but others define it as materials that can generate a response, in their properties or geometries, when submitted to an external stimulus, such as temperature, $\mathrm{pH}$ variation, etc. [11]. In this research, the second definition will be approached.

The chitosan (molecular structured approached in Figure 1) hydrogel has been receiving attention of researchers due to its ability in reaching the complexity of living tissues [12]. For this reason, this material is studied for its application in the biomedical area, as well as it use in devices capable of releasing drugs into the human body [13].

This ability is mainly due to the high capacity of water absorption and the fact that its characteristics can be easily molded. Thus, the chitosan hydrogel is commonly applied in tissue engineering and in controlled drug delivery systems [14]. However, some properties, such as mechanical strength, do not favor certain applications [15]. Thereby, composite hydrogels are often used to obtain more interesting characteristics, for example, hydrogels formed by chitosan and polyvinylpyrrolidone. 


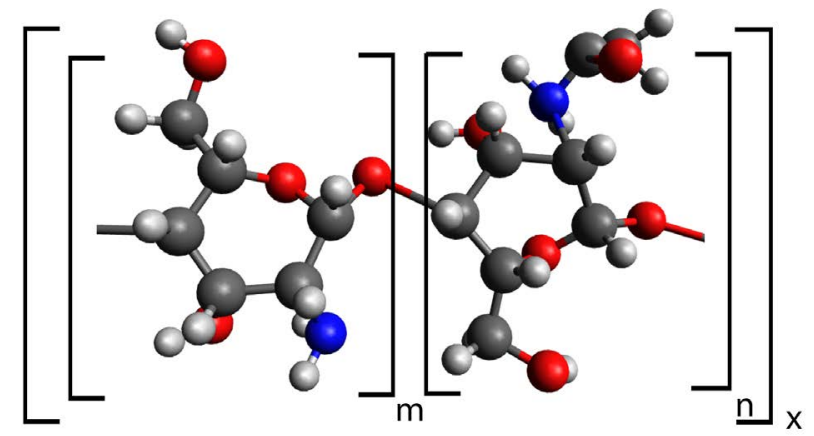

Figure 1. Molecular structure of chitosan (Blue-Nitrogen, Grey-Carbon, Red-Oxygen, White-Hydrogen).

Polyvinylpyrrolidone (PVP) is a synthetic polymer formed from the vinylpyrrolidone monomer. Such material is bulky, non-ionic and it is in the form of white powder at room temperature [16]. Part of its molecule is hydrophilic due to pyrrolidone, and part is hydrophobic due to alkyl groups [17]. The molecular structure is approached in Figure 2.

This polymer is soluble in water and has a humidifying property, which implies in its use in the adhesives formulation, envelopes, seals, etc. In addition, the material is biocompatible and composes various medicaments as an excipient and it is used as a blood plasma expander [16].

There are several hydrogels containing PVP in their structure, such as PVP, hydroxyapatite and polyvinyl alcohol hydrogels, which have applications in biology [18] and PVP and polyacrylic acrylic hydrogels, which are used in the production of nanofibers [19].

Hydrogels composed of PVP and chitosan are called responsive $\mathrm{pH}$, because its volume changes due to this factor [20]. For this reason, this type of hydrogel has been studied for application in $4 \mathrm{D}$ printing [21].

$4 \mathrm{D}$ Printing is a new type of additive manufacturing that has one extra dimension, which is described as the ability of transformation. This technique is able to print materials capable of changing over time and a material system that can transform its shape directly after being printed (change color, shape, properties, etc). Therefore, $4 \mathrm{D}$ printing doesn't produce static materials, but dynamic objects that are programmably active and that transform independently [22].

In order to collaborate with the studies of smart materials that can be applied in $4 \mathrm{D}$ printing, this paper approach the synthesis of sensible hydrogels of chitosan/PVP, its behavior in relation to $\mathrm{pH}$ and the explanation of the phenomena observed through computational modeling.

\section{Materials}

To synthesize the chitosan/PVP hydrogel, chitosan (molecular weight $=200)$ and polyvinylpyrrolidone K30 (molecular weight $=40,000$ ) of the Synth brand, and $25 \%$ glutaraldehyde $($ molecular weight $=100.12)$ of Sigma-Aldrich were used. 


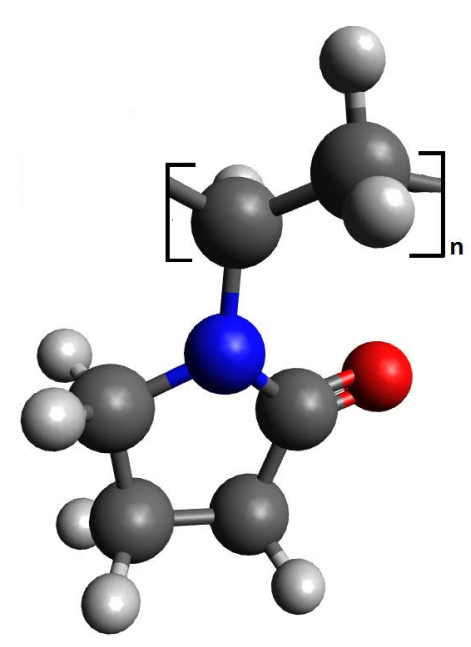

Figure 2. Molecular structure of polyvinylpyrrolidone (Blue-Nitrogen, Grey-Carbon, Red-Oxygen, White-Hydrogen).

\section{Methods}

\subsection{Synthesis of Chitosan/PVP Hydrogel}

For the synthesis of the hydrogel of chitosan and polyvinylpyrrolidone, the paper of Risbud, Hardikar and Bhonde (2000) was used as base [23] once it describes a simple method to produce hydrogels with interesting areas of application, like in growth modulation of fibroblasts and membranes [23] [24].

Thus, an aqueous solution of $196 \mathrm{ml}$ of $0.1 \mathrm{M}$ acetic acid was prepared in a beaker. Such beaker was placed on a magnetic stirrer ( $360 \mathrm{rpm})$ and $4 \mathrm{~g}$ of chitosan were slowly added to the system. Then, it was covered with film plastic and the stirring continued for 24 hours. After such period, the solution was name solution 1.

In another beaker, $192 \mathrm{ml}$ of distilled water were added and placed on a magnetic stirrer.

Thus, $8 \mathrm{~g}$ of PVP were also slowly added. The system was covered with film plastic and allowed to stir for 3 hours. Such solution was named solution 2 .

Then, solutions 1 and 2 were mixed in different ratios (1: 1, 7:3 and 3:7 (volume/volume)). These solutions were named as $3 \mathrm{~A}, 3 \mathrm{~B}$ and $3 \mathrm{C}$, respectively.

An aqueous solution of $3 \mathrm{ml}$ of $25 \%$ glutaraldehyde was added to solutions 3 (1 ml each). Such solutions were placed on a magnetic stirrer for 10 minutes at room temperature. After that, the solutions were placed in Petri dishes which were dried at $32^{\circ} \mathrm{C}$ for $72 \mathrm{~h}$ in a sterile atmosphere. These hydrogels were named Hydrogel 1, Hydrogel 2 and Hydrogel 3, as shown in Table 1.

\section{2. pH Sensitivity Tests of Chitosan/PVP Hydrogels}

In order to analyze the behavior of the hydrogels at different pHs, six samples of each hydrogel were collected, their masses were measured and, in pairs, they were immersed in solutions of $\mathrm{pH} 3,3 ; 7.3$ and 9.6, as shown in Table 2. These 
Table 1. Compositions of the hydrogels synthesized.

\begin{tabular}{cccc}
\hline & Chitosan $(\mathrm{ml})$ & PVP $(\mathrm{ml})$ & Glutaraldehyde $(\mathrm{ml})$ \\
\hline Hydrogel 1 & 50 & 50 & 1 \\
Hydrogel 2 & 70 & 30 & 1 \\
Hydrogel 3 & 30 & 70 & 1 \\
\hline
\end{tabular}

Table 2. Relation of Masses of Samples Collected.

\begin{tabular}{lccc}
\hline & Sample Name & Hydrogel Dry Mass $(\mathrm{g})$ & pH of Test \\
\hline Hydrogel 1 & H1AX & 1.5030 & 3.3 \\
Hydrogel 1 & H1AY & 3.0440 & 3.3 \\
Hydrogel 1 & H1BX & 2.2565 & 7.3 \\
Hydrogel 1 & H1BY & 3.0588 & 7.3 \\
Hydrogel 1 & H1CX & 2.7306 & 9.6 \\
Hydrogel 1 & H1CY & 3.1892 & 9.6 \\
Hydrogel 2 & H2AX & 4.1736 & 3.3 \\
Hydrogel 2 & H2AY & 1.8570 & 3.3 \\
Hydrogel 2 & H2BX & 2.5134 & 7.3 \\
Hydrogel 2 & H2BY & 3.4033 & 7.3 \\
Hydrogel 2 & H2CX & 1.8634 & 9.6 \\
Hydrogel 2 & H2CY & 3.2295 & 9.6 \\
Hydrogel 3 & H3AX & 1.7269 & 3.3 \\
Hydrogel 3 & H3AY & 3.3036 & 3.3 \\
Hydrogel 3 & H3BX & 2.0389 & 7.3 \\
Hydrogel 3 & H3BY & 2.5683 & 7.3 \\
Hydrogel 3 & H3CX & 2.6103 & 9.6 \\
Hydrogel 3 & H3CY & 2.7704 & 9.6 \\
\hline
\end{tabular}

solutions were prepared with distilled water and the $\mathrm{pHs}$ were handled with the aid of $\mathrm{NaOH}$ and $\mathrm{HCl}$.

\subsection{Swelling Results Analysis}

The bodies were removed from the solution after $36 \mathrm{~h}$, the surface of the material was dried with paper and the mass was measured again to determine the percentage of water absorbed. Thus, the following formula was used to determine the water absorbed in the hydrogels:

$$
\% \text { of water absorbed }=\left(\frac{\text { Hydrogel swollen mass }}{\text { Hydrogel dry mass }}\right) \times 100 \%
$$

\subsection{Modeling Step}

There is currently little research related to the molecular simulation of hydrogels 
at the nanoscale [25]. So, in order to contribute to the studies related to the computational chemistry of hydrogels and obtain a better visual comprehension of the phenomenon observed in the experiment, the modeling of Polyvinylpyrrolidone (PVP), chitosan and hydrogel chitosan/PVP was carried out by using the Avogadro software (2018 version).

It is a free license software that allows to edit, visualize and simulate threedimensional molecules, in order to reveal and study details at microscopic levels and to provide information about chemical properties, reactions and laws [26]. In addition, it has simpler manipulation tools for software such as VMD, NAMD and LAMMPS, allowing modeling and simulation of chemical structures in a simple way. In addition, as a way of visualizing the reaction of the hydrogel to different $\mathrm{pH}$ values, the same software was used to represent the chitosan/ PVP molecule in situations of protonation and deprotonation, as well as its interaction with water molecules.

\section{Results and Discussion}

\subsection{Rigidity and Deacetylation Approach}

After prepare solution 1, it was possible to see some areas with chitosan accumulation, what indicates that the polymer wasn't totally dissolved, as shown in Figure 3.

Consequently, after the synthesis of hydrogels 1, 2 and 3, it was possible to perceive that the higher the amount of chitosan in the hydrogel, more rigid was hydrogel.

The rigidity due high values of chitosan is related to the degree of deacetylation, which consists in the transformation of an acetamino group $\left(-\mathrm{NCOCH}_{3}\right)$ into an amine group $\left(-\mathrm{NH}_{2}\right)$, as shown in Figure 4 [27].

Thereby, it is possible to conclude that the chitosan used in the experiment hasn't got a high degree of deacetylation since the higher the degree of chitosan deacetylation, the greater its flexibility is [28]. This happens because, when such a value is low, there is difficulty in the spatial rotation of the glycosidic bond due to the presence of several- $\mathrm{NCOCH}_{3}$ units, which causes a high steric hindrance and consequently stiffening of the material. However, when the number of amine units is high, the rotation of the glycosidic bond is favored since the steric hindrance is smaller, allowing for greater flexibility [29].

It is important to mention that not all acetamine groups turn into amine group, that is why chitosan is a copolymer ( $N$-acetyl-glucosamine + glucosamine).

After the experiment had been carried out, it was also detected that the higher the proportion of chitosan in the hydrogel (in relation to the proportion of PVP), the greater the stiffness and the gelatinous characteristic of it. So, the hydrogel 2 presented the highest stiffness, hydrogel 3 was quite liquid and hydrogel 1 had intermediate characteristics between those previously mentioned.

Such phenomenon is associated with the fact that amine groups are capable of 


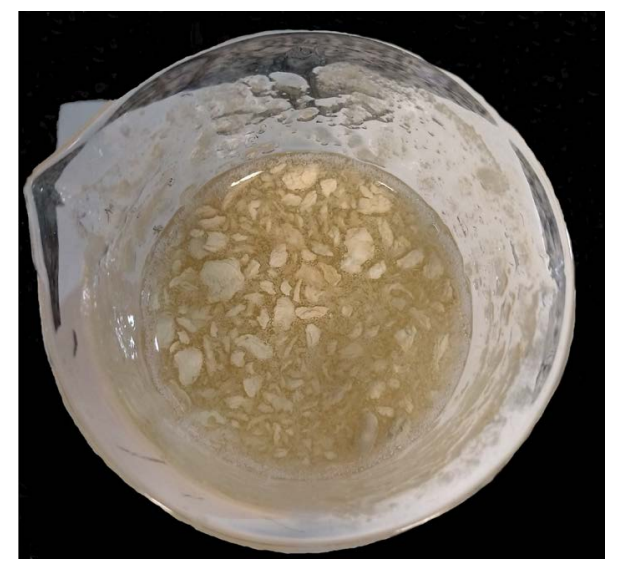

Figure 3. Solution 1 with chitosan accumulation.

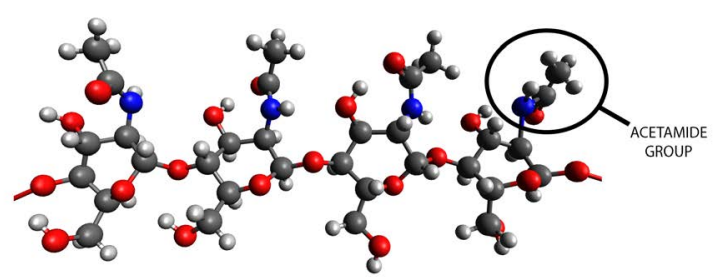

CHITIN

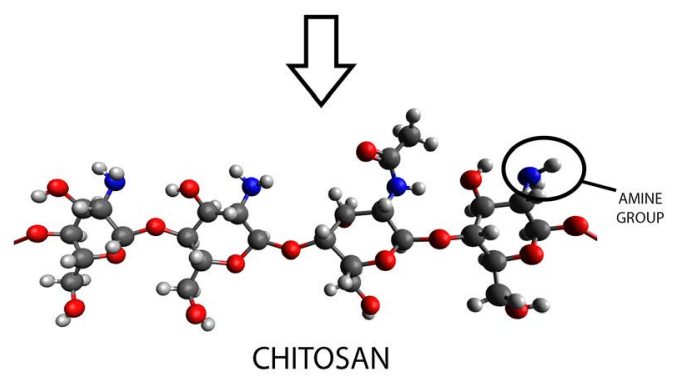

Figure 4. Deacetylation process for the production of chitosan from chitin (Blue-Nitrogen, Grey-Carbon, Red-Oxygen, White-Hydrogen).

forming crosslinks. Thus, the more units of such a group are present, the greater the gelation rate and the lower the gelation temperature [30].

Thereby, it was difficult to handle hydrogel 3 samples because they were quite brittle and sensitive, as it is possible to see in Figure 5 and Figure 6. Moreover, when inserted in the solutions of different $\mathrm{pHs}$, these were broken to numerous pieces, which made the measurement of absorbed water difficult. Hence, it became essential to disregard hydrogel 3 for the analyses, since its results were not reliable and conclusive.

\subsection{Analysis of Swelling in Relation to $\mathrm{pH}$}

After the experiment presented, the Average Mass of the samples of the same hydrogel that were immersed in the same $\mathrm{pH}$ was calculated. Thus, it was possible to determine the percentage of water absorbed, presented in Table 3. 


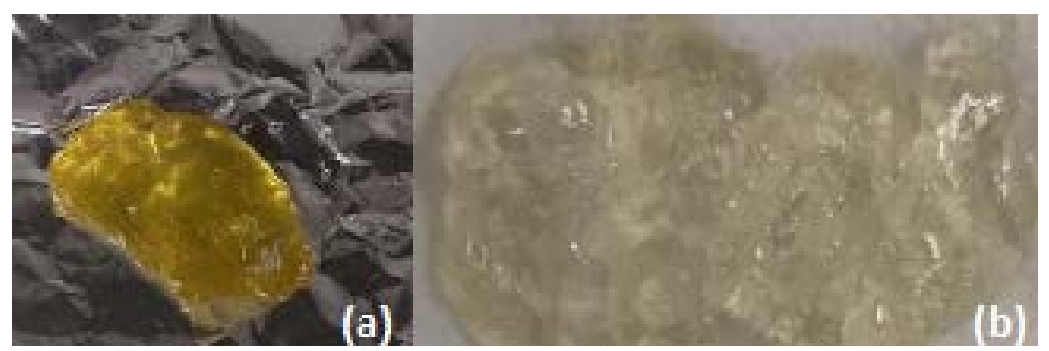

Figure 5. Hydrogel 3AY before (a) and after (b) contact with pH 3, 3 solution.

Table 3. Relation between mass of dry and swollen hydrogels.

\begin{tabular}{ccccc}
\hline Sample Name & $\begin{array}{c}\text { Average Mass of the } \\
\text { Dry Hydrogel (g) }\end{array}$ & $\begin{array}{c}\text { Average Mass of the } \\
\text { Swollen Hydrogel (g) }\end{array}$ & pH & $\begin{array}{c}\text { \% water } \\
\text { absorbed }\end{array}$ \\
\hline H1A & 2.2735 & 8.2776 & 3.3 & $364 \%$ \\
H1B & 2.6577 & 10.1585 & 7.3 & $382 \%$ \\
H1C & 2.9599 & 11.1860 & 9.6 & $378 \%$ \\
H2A & 3.0253 & 12.8863 & 3.3 & $427 \%$ \\
H2B & 2.9584 & 12.0519 & 7.3 & $407 \%$ \\
H2C & 2.5465 & 9.8933 & 9.6 & $388 \%$ \\
H3A & 2.5153 & 15.2238 & 3.3 & $605 \%$ \\
H3B & 2.3036 & 23.7500 & 7.3 & $1031 \%$ \\
H3C & 2.904 & 27.8738 & 9.6 & $1036 \%$ \\
\hline
\end{tabular}

By analyzing Table 3, it is possible to notice that all samples expanded when in contact with solutions of different pHs. To understand such phenomenon, it is necessary to analyze the structure of PVP and chitosan in order to conclude if only one or both of them are responsible for the hydrogel sensibility to $\mathrm{pH}$.

The glucosamine part of the structure of chitosan, approach in Figure 1, shows that it has amino groups capable of protonating and deprotonating. Such aspect is responsible for the material sensitivity to $\mathrm{pH}$ variation [31]. In chitosan, at low pHs (usually below 6), its amine groups are protonated as a quaternary ammonium salt with positive charges. And at high $\mathrm{pH}$ values (usually above 6), they are deprotonated [6].

The pka is the magnitude associated with this phenomenon so that this value determines at what $\mathrm{pH}$ this transition occurs and depends directly on the degree of deacetylation during chitosan production [6]. In general, the pka of the amino groups of chitosan is between 6.2 and 6.3 [32].

In addition, the variation in the volume of the material occurs in the sense of minimizing the repulsion of the charges present in the chemical structure [33].

However, PVP structure approach in Figure 2, shows that it is a non-ionic polymer [34], what means that it can't pronotate/deprotonate, and consequently, it is not responsible for the sensibility to $\mathrm{pH}$ presented by the hydrogel.

As a way of visualizing the phenomenon, the reaction below was developed using the Avogadro software, based on the hydrogel formation proposed by 
Zhang, Jin, Li, Zhang \& Wu (2018), so that the geometry of the structure was constructed and adjusted according to the optimization tool geometry provided by the software itself, minimizing the total energy of the molecule. Such modelling can be observed in Figure 7 and the red, blue, gray and white spheres represent, respectively, the oxygen, nitrogen, carbon and hydrogen atoms.

The modeling of the chitosan/PVP complex was also developed under $\mathrm{pH}$ values of 3.3; 7.3 and 9.6, as approached in Figure 8, where the prominent figures represent the amino groups in situations of protonation and deprotonation.

Analyzing the hydrogels 1 and 2, it is also noted that the volumetric expansion varied according to the different ranges of $\mathrm{pHs}$ and there was no pattern in relation to these samples. In this way, bibliographical references were consulted to understand what behavior was appropriate.

Firstly, it was raised the hypothesis that the hydrogel 2 presented the most coherent behavior since, because it possessed more chitosan in its composition, it was more rigid and easier to handle, besides demonstrating a better consistency of gel.

After the search, the hypothesis was confirmed. That is, as in Risbud, HdardikarBhat and Bhonde (2000), it was expected that the volumetric variation of the materials studied would respond negatively as the $\mathrm{pH}$ increased.

In addition, it was expected that the higher the proportion of chitosan in the hydrogel, the greater its sensitivity to $\mathrm{pH}$, ie, the greater its swelling mechanism, which could also be confirmed when comparing hydrogels 1 and 2 .

\section{Conclusions}

Hydrogels that have chitosan in their composition always showed sensitivity to the $\mathrm{pH}$ since this material has groups capable of protonating and deprotonating. This effect implies an increase in volume due to some factors, such as the occurrence of electrostatic repulsion among ionized groups.

As PVP does not present groups with this characteristics, its application does not attribute sensitivity to the hydrogel. Thus, the tests carried out in the laboratory of the Federal University of $\mathrm{ABC}$ showed that the higher the proportion of chitosan in the hydrogel, in relation to the PVP, the greater its swelling as well as confirming that the swelling mechanism of the hydrogel is unfavorable to increasing the $\mathrm{pH}$ of the medium.

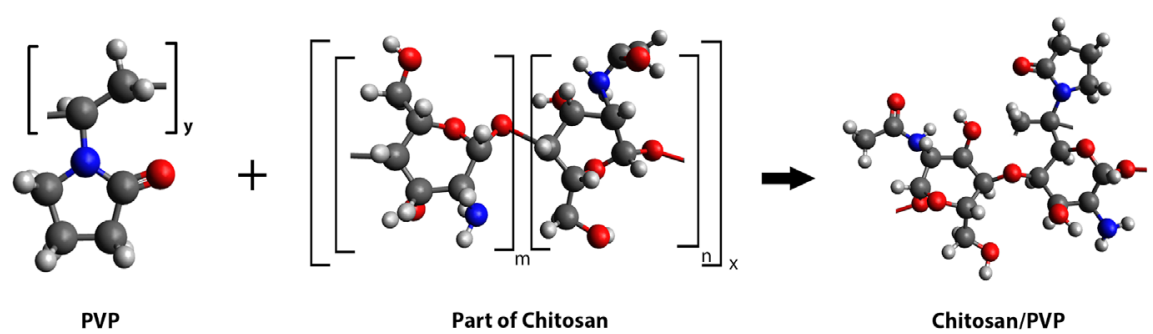

Figure 6. Demonstration of the formation of Chitosan/PVP Structure. 


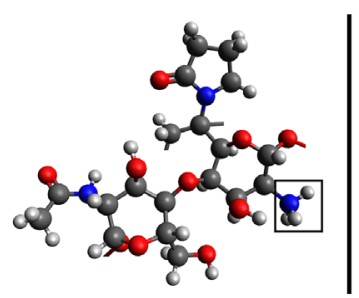

$\mathrm{pH}=\mathbf{3 . 3}$

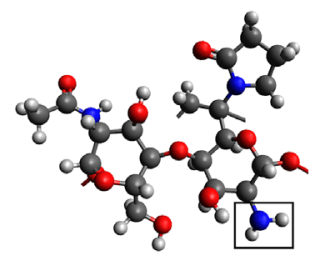

$\mathbf{p H}=7.3$

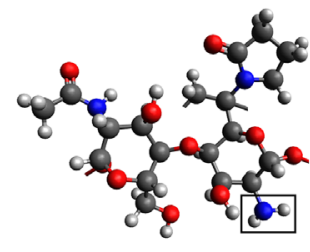

$\mathrm{pH}=9.6$

Figure 7. Demonstration of Hydrogel under different $\mathrm{pH}$ values.

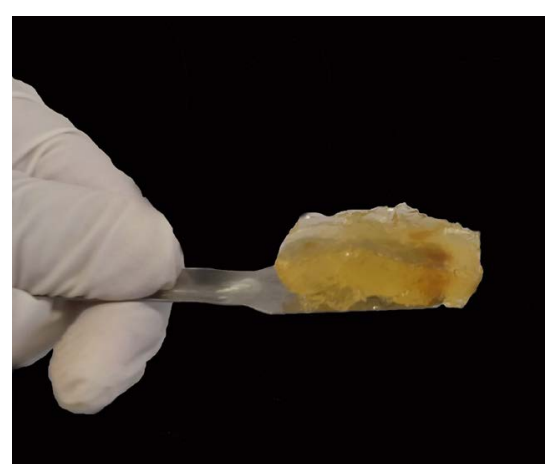

Figure 8. Hydrogel H3AX before being submitted to aqueous solution.

When synthesizing three different types of hydrogels of chitosan:PVP with rations equal to 1:1, 7:3 and 3:7 (volume/volume), it was possible to conclude that the hydrogel of easier handling and execution of the experiment was that of 7:3 due to its stiffness. As it was also shown to be the most interesting hydrogel for paper article proposal due to its greater sensitivity to external $\mathrm{pH}$.

\section{Acknowledgements}

Thank FAPESP, CNPq, the chemistry didactic laboratory at UFABC and the research group "4D Printing and Biomimetics" for the support.

\section{Conflicts of Interest}

The authors declare no conflicts of interest regarding the publication of this paper.

\section{References}

[1] Palumbo, F.S., Volpe, A.B., Cusimano, M.G., Pitarresi, G., Giammona, G. and Schillici, D. (2015) A Polycarboxylic/Amino Functionalized Hyaluronic Acid Derivative for the Production of $\mathrm{pH}$ Sensible Hydrogels in the Prevention of Bacterial Adhesion on Biomedical Surfaces. International Journal of Pharmaceutics, 478, 70-77. https://doi.org/10.1016/j.ijpharm.2014.11.015

[2] Shay, T., Veley, O.D. and Dickey, M.D. (2018) Soft Electrodes Combining Hydrogel and Liquid Metal. Soft Matter, 14, 3296-3303. https://doi.org/10.1039/C8SM00337H

[3] Larrañeta, R., Stewart, S., Ervine, M., Al-Kassasbeh, R. and Donnelly, R.F. (2018) 
Hydrogels for Hydrophobic Drug Delivery. Classification, Synthesis and Applications. Journal of Functional Biomaterials, 13, 2-20. https://doi.org/10.3390/jfb9010013

[4] Riva, R. and Jerome, C. (2014) Chitosan: A Versatile Platform for Pharmaceutical Applications.

https://www.sigmaaldrich.com/technical-documents/articles/materials-science/chit osan-a-versatile-platform.html

[5] Nwosu, C.J., Hurst, G.A. and Novakovic, K. (2015) Genipin Cross-Linked Chitosan-Polyvinylpyrrolidone Hydrogels: Influence of Composition and Postsynthesis Treatment on $\mathrm{pH}$ Responsive Behaviour. Advanced Materials Science Engineering, 2015, Article ID: 621289. https://doi.org/10.1155/2015/621289

[6] Ribeiro, M.J.P. (2012) Desenvolvimento de um Novo Hidrogel de Quitosano para Futura Aplicaçãocomo Substituto de Pele. Master Thesis, Universidade da Beira Interior, Covilhã.

[7] Hu, Y. (2018) Chitosan Gel Incorporated Peptide-Modified AuNPs for Sustained Drug Delivery with Smart pH Responsiveness. Journal of Materials Chemistry B, 5, 1174-1181. https://doi.org/10.1039/C6TB02098D

[8] Rodrigues, I.R. (2006) Síntese e caracterização de redepoliméricas a base de Quitosana e PVP e PVA para aplicaçãonaliberaçãocontrolada de fármacos. Master Thesis, Universidade Federal do Rio Grande do Sul, Porto Alegre.

[9] Kim, Y.S., Tamate, R., Akimoto, A.M. and Yoshida, R. (2016) Recent Developments in Self-Oscillating Polymeric Systems as Smart Materials: From Polymers to Bulk Hydrogels. Materials Horizon, 4, 38-54. https://doi.org/10.1039/C6MH00435K

[10] Khoo, Z.X. Teoh, J.E.M., Liu, Y., Chua, C.K., Yang, S.J., Leong, K.F. and Yeong, W.Y. (2015) 3D Printing of Smart Materials: A Review on Recent Progresses in 4D Printing. Virtual and Physical Prototyping, 10, 103-122. https://doi.org/10.1080/17452759.2015.1097054

[11] Dahlberg, T., Stangner, T., Zhang, H., Wiklund, K., Lundberg, P., Edman, L. and Andersson, M. (2018) 3D Printed Water-Soluble Scaffolds for Rapid Production of PDMS Microfluidic Flow Chambers. Scientific Reports, 8, Article No. 3372. https://doi.org/10.1038/s41598-018-21638-w

[12] Moura, M.J.C. (2015) Preparação e Caracterização de Hidrogéis de Quitosano para Administraçãopor Via Injetável. Master Thesis, Universidade de Coimbra, Coimbra.

[13] Yadollahia, M., Farhoudiana, S. and Namazi, H. (2015) One-Pot Synthesis of Antibacterial Chitosan/Silver Bio-Nanocomposite Hydrogel Beads as Drug Delivery Systems. International Journal of Biological Macromolecules, 79, 37-43. https://doi.org/10.1016/j.ijbiomac.2015.04.032

[14] Chen, N.C., Lin, W.J., Ling, T.Y. and Young, T.H. (2017) Sustained Release of Adipose-Derived Stem Cells by Thermosensitive Chitosan/Gelatin Hydrogel for Therapeutic Angiogenesis. Acta Biomaterialia, 51, 258-267.

https://doi.org/10.1016/j.actbio.2017.01.060

[15] Andrade, J.B. (2018) Polivinilpirrolidona. http://qnint.sbq.org.br/qni/popup_visualizarMolecula.php?id=jSk7dFagsfhIxlmNiC wDBhbFrE2eVdwlzWIRjNS4OJDbghVowVt3p8G3OYZMhLwlzpMtkTUulZA5zNo 9VHGWwQ

[16] Koczkur, K.M., Mourdikoudis, S., Polavarapu, L. and Skrabalak, S.R. (2015) Polyvinylpyrrolidone (PVP) in Nanoparticle Synthesis. Dalton Transactions, 44, 17883 17905. https://doi.org/10.1039/C5DT02964C 
[17] Ma, Y., Bai, T. and Wang, F. (2016) The Physical and Chemical Properties of the Polyvinylalcohol/Polyvinylpyrrolidone/Hydroxyapatite Composite Hydrogel. Materials Science Engineering C, 59, 948-957. https://doi.org/10.1016/j.msec.2015.10.081

[18] Lubasova, D., Niu, H., Zhao, X. and Lin, T. (2015) Hydrogel Properties of Electrospunpolyvinylpyrrolidone and Polyvinylpyrrolidone/Poly(Acrylic Acid) Blend Nanofibers. Royal Society of Chemistry Advances, 67, 54481-54487. https://doi.org/10.1039/C5RA07514A

[19] Vaghani, S.S. and Patel, M.M. (2011) PH-Sensitive Hydrogels Based on Semi-Interpenetrating Network (Semi-IPN) of Chitosan and Polyvinyl Pyrrolidone for Clarithromycin Release. Drug Development and Industrial Pharmacy, 37, 11160-11169. https://doi.org/10.3109/03639045.2011.563422

[20] Mandon, C.A., Blum, L.J. and Marquette, C.A. (2017) 3D-4D Printed Objects: New Bioactive Material Opportunities. Micromachines, 8, 102. https://doi.org/10.3390/mi8040102

[21] Tibbits, S. (2014) 4D Printing: Multi-Material Shape Change, Architecture and Design. Architectural Design, 84, 116-121. https://doi.org/10.1002/ad.1710

[22] Risbud, M., Hardikar, A. and Bhonde, R. (2000) Growth Modulation of Fibroblasts by Chitosan-Polyvinyl Pyrrolidone Hydrogel: Implications for Wound Management? Journal of Biosciences, 25, 25-30. https://doi.org/10.1007/BF02985178

[23] Risbud, M.V. and Bhat, S.V. (2001) Properties of Polyvinyl Pyrrolidone/ $\beta$-Chitosan Hydrogel Membranes and Their Biocompatibility Evaluation by Haemorheological Method. Journal of Materials Science: Materials in Medicine, 12, 75-79. https://doi.org/10.1023/A:1026769422026

[24] Ou, X., Han, Q., Dai, H.H. and Wang, J. (2015) Molecular Dynamic Simulations of the Water Absorbency of Hydrogels. Journal of Molecular Modeling, 21, 231. https://doi.org/10.1007/s00894-015-2784-0

[25] Rayan, B. and Rayan, A. (2017) Avogadro Program for Chemistry Education: To What Extent Can Molecular Visualization and Three-Dimensional Simulations Enhance Meaningful Chemistry Learning. Journal of Chemical Education, 5, 136-141. https://doi.org/10.12691/wjce-5-4-4

[26] Joúwiak, T., Filipkowsk, U., Szymczyk, P. and Kuxzajowska-Zadrozna, M. (2016) The Influence of Chitosan Deacetylation Degree on Reactive Black 5 Sorption Efficiency from Aqueous Solutions. Political Science Journal Database, 21, 83-92. https://doi.org/10.15259/PCACD.21.08

[27] Kerch, G., Zicans, J., Meri, R.M., Stunda-Ramava, A. and Jakobson, E. (2015) The Use of Thermal Analysis in Assessing the Effect of Bound Water Content and Substrate Rigidity on Prevention of Platelet Adhesion. Journal of Thermal Analysis and Calorimetry, 120, 533-539. https://doi.org/10.1007/s10973-014-4244-y

[28] Hamdi, M., Nasri, R., Hakii, S., Nigen, M., Li, S. and Nasri, M. (2019) Acetylation Degree, a Key Parameter Modulating Chitosan Rheological, Thermal and FilmForming Properties. Food Hydrocolliods, 87, 48-60. https://doi.org/10.1016/j.foodhyd.2018.07.027

[29] Tsai, M., Cheng, H., Yu, H. and Lin, Y.T.Y. (2011) Effect of Chitosan Characteristics and Solution Conditions on Gelation Temperatures of Chitosan/2-Glycerophosphate/ Nanosilver Hydrogels. Carbohydrate Polymers, 84, 1337-1343. https://doi.org/10.1016/j.carbpol.2011.01.035

[30] Risbud, M.V., Hdardikar, A.A., Bhat, S.V. and Bhonde, R.R. (2000) PH-Sensitive Freeze-Dried Chitosan-Polyvinyl Pyrrolidone Hydrogels as Controlled Release System for Antibiotic Delivery. Journal of Controlled Release, 68, 23-30. 
https://doi.org/10.1016/S0168-3659(00)00208-X

[31] Kim, M.H. (2017) Incorporation of Charged Polysaccharide Binders to Improve Capacitive Deionization Performance. Master Thesis, University of Illinois at Urbana-Champaign, Chicago.

[32] Zhang, W., Jin, X., Li, H., Zhang, R. and Wu, X. (2018) Injectable and Body Temperature Sensitive Hydrogels Based on Chitosan and Hyaluronic Acid for $\mathrm{pH}$ Sensitive Drug Release. Carbohydrate Polymers, 186, 82-90.

https://doi.org/10.1016/j.carbpol.2018.01.008

[33] Ramamoorth, C. and Rajendran, V. (2017) Effect of Surfactants Assisted $\mathrm{Co}_{3} \mathrm{O}_{4}$ Nanoparticles and Its Structural, Optical, Magnetic and Electrochemical Properties. Optik, 145, 330-335. https://doi.org/10.1016/j.ijleo.2017.07.058

[34] Chemistry, A. (2019) Molecular Mechanics \& Force Field. https://avogadro.cc/docs/optimizing-geometry/molecular-mechanics 